\title{
UCLA
}

Mester

Title

Con o sin calzón

Permalink

https://escholarship.org/uc/item/09h6b98w

Journal

Mester, 16(1)

Author

Lizárraga, W. Enrique

Publication Date

1987

DOI

10.5070/M3161013809

Copyright Information

Copyright 1987 by the author(s). All rights reserved unless otherwise indicated. Contact the author(s) for any necessary permissions. Learn more at https://escholarship.org/terms

Peer reviewed 


\section{Con o sin calzón}

- ¿A la casa de la Lucía?

Sí, sí, lo acompañaría. Cómo no. Aunque el Oso seguía serio, con la vista enterrada en el mismo montículo de arena, pese a que el Fernando buscaba la forma de asegurarle de que ni por un segundo había dudado de su determinación, tampoco de su valentía, mucho menos de su, digamos, amor por la Lucía. Era más que nada el suegro, don Armando. Una cosa era decir vamos donde la Lucía y otra muy distinta hacerlo. Porque en el mejor de los casos el suegro simplemente no los recibía. Más valía no pensar en lo peor. Pero el Oso no cambiaba de pose. Ceño fruncido, mirada penetrando nada, como si con esa actitud apretara el botón de algún mecanismo secreto que automáticamente borra aquello que uno no desea en el pasado, en el presente también. Ajá, eso era. Algo opuesto, sí, algo totalmente opuesto a las repeticiones de los goles en la tele. Se aprieta el botón. Se repite la escena. Y no hay gol. El arquero ha volado perfecto hasta el ángulo por donde la pelota llegó a las redes. El Fernando tenía que comprender que al Oso le hubiera gustado apretar aquel botón y ya: la Lucía a su lado, mortalmente enamorada de él. Las palabras sobraban. La cosa era que no tenía ningún mecanismo secreto ni ocho cuartos y por eso se quedaba así, indiferente al mundo, padeciendo en soledad impertérrita la injusticia universal sin botón salvador.

No obstante, a pesar de la poca pericia del Fernando para sortear la aparente inexpugnabilidad del Oso, y el talento de éste para mantener el mismo gesto en silencio congelado, el plan quedó fijado inamoviblemente para la misma noche. Se reunirían detrás de la casa de la Maruja. Ni una palabra a los demás. Casi no pudiendo reprimir el entusiasmo, el Oso se comprometió a traer una cajetilla de cigarrillos, nuevecita.

$-i$ Te has puesto perfume?

Sin embargo no fue eso lo que dijo el Fernando al acudir a la cita. Hubiera sido condenar la jornada al silencio desconsolado del Oso. Más bien mencionó algo sobre la luna, algo así como menos mal que esta noche no hay luna. Aunque había que hacer algo urgente con el perfume. Lo peor era que parecía de mujer. Un error así en una primera cita podía ser fatal. El Fernando no tenía ninguna experiencia en estas lides, pero el perfume era insoportable. Con ese olor, además, ondeando alrededor del Oso, sería prácticamente imposible disimular las verdaderas intenciones de la visita. Ni por milagro el suegro accedería a creer en el burdo e inofensivo pretexto de que sólo venían a jugar cartas. La Lucía los había invitado. Sí, señor. Les encantaba jugar cartas. Sí, señora. Y se acomodarían angelicalmente frente a la Lucía y su mamá. En la cabecera estaría bien aposentado don Armando; al otro extremo, la tía; el hermanito por todos lados. Y el perfume metiéndose por las narices de todos. No, señor. Había que hacer algo. El Oso se adelantó a poner en marcha la noche: 
- Bajemos ¿no? Nos fumamos un pito en la orilla y ya veremos.

Mientras descendían a la orilla el Fernando volvió a repetir su comentario sobre la luna y observó en la tranquilidad del mar un buen presagio. Después de lo cual el Oso no pudo refrenar su deseo de hablar mal del suegro. Antes de llegar al límite donde la arena se va humedeciendo, se sentaron. El Oso desvirginó la cajetilla y encendió el primer cigarrillo.

- ¿Son mentolados?

El Oso entendió la petición y sonrió. Pero no le pasó el cigarrillo hasta después de haber dado tres pitadas cadenciosas, largas y profundas, como le corresponde a un enamorado en esas circunstancias. Echaba el humo uniformemente por la nariz y la boca con mangnífico control, la frente arrugada, la mirada esta vez en el mismo infinito. El Fernando lo miraba, quizás intrigado; en cierta medida halagado también. El Oso confiaba en él. A pesar de los dos años de diferencia de edad, insalvables, eran amigos. Qué sentiría en aquellos momentos tan, tan. Seguramente cuando le tocara el turno a él, estaría mucho más nervioso. No, lo de la Yolanda no era lo mismo. Acaso podía comparar a la Yolanda con la Lucía. Al recibir el cigarrillo se aplicó a imitar a su compañero con pasión. No obstante, era consciente de no poder arrugar la frente con tanta madurez, mostrar en cada pitada ese dolor tan hondo, esa emoción que lo hacía al Oso un hombre tan así. El humo le salía por la boca nomás. Todavía le faltaba mucha práctica para sacarlo por la nariz.

- ¿Sabes lo que más me gusta de la Lucía?

Cuenta, cuenta. Para qué había venido con él si no. Los dos ahí, a una distancia prudente de donde los demás ya debían de estar reunidos, todavía muy lejos de la casa de la Lucía, la última casa caminando con el mar a la derecha. Seguramente los otros ya andarían preguntándose por la suerte de los dos. Hasta habría apuestas. Sí o no. Quién da más. No la pasarían nada mal especulando sobre la cara del Oso a la hora de saludar al suegro. Por lo demás, había sin dudas muchos celos. A alguno de ellos, por lo menos al Juan y al Edy no les hubiere caído mal ser el primero en la historia de la Lucía. No se le conocía ningún amor en su pasado. No era coqueta ni mala gente. Con el sol la piel se le ponía dorada; el pelo, rubio, como la mamá que era italiana. No había heredado nada del papá. Su cuerpo era perfecto, nada demás ni de menos. Pero sobre todo, era angelical. Aun con su bikini verde, el que apenas le cubría el mínimo indispensable, seguía siendo pura. Cada vez que el Chino la veía repetía, ahí va $\mathrm{mi}$ angelito de la guarda.

- ¿Sabes? me gusta todo, todito.

$\mathrm{Y}$ encendió otro cigarrillo con la urgencia de quien necesita sentir algo caliente en los labios, en el pecho, el corazón, por supuesto. Inspiradísmo, más que nada emocionado por haber percibido la imagen de la Lucía tan irresistible, dio una pitada más larga que nunca, casi infinita. Sin hacer el menor gesto de asfixia, medio cigarrillo desapareció en aquel suspiro. Mas no soltó el humo sino hasta mucho después, cuando el ceño fruncido hubo 
cobijado todo su amor adolorido por el silencio. Porque así era él. Nadie podía aspirar tanto como él, por eso era el que más aguantaba bajo el agua, nunca se cansaba de nadar. Por lo tanto nadie podía amarla tanto como él. Que alguien se atreviera a desafiarlo, a ver, que volara de palo a palo para tapar el gol más imparable del mundo. No, nada de Oso ni ocho cuartos. El era la pantera del arco. Jugaría para la selección nacional y luego el Palmeiras del Brasil, su equipo favorito, lo contrataría con sueldo millonario. Ah, pero no sólo sería arquero. Además terminaría su carrera de ingeniería aeronáutica. No iba a ser como los demás deportistas. El iba a tener una profesión para cuando decidiera entregar el equipo. Así, cuando fuera famoso, querido y respetado por todos, podría volar, ya no de palo a palo pero por lo menos de país en país en un avión que él mismo se iba a construir. Cruzar el Atlántico.

- ¿Alguna vez has besado, huevón?

La pregunta lo agarró al Oso en pleno vuelo, sobre el mar, en el momento exacto en que la Lucía le daba un beso, como la caricia de un angel, a cinco mil metros de altura.

No, en realidad no había besado de lleno. Lo extraño era sentir que sí. Le pasó lo mismo hace unos días cuando la Carmen, siempre metete, le pidió que llenara el cuestionario, que no se hiciera de rogar. No valen mentiras, había agregado aun. Sin embargo, más que contestar las preguntas, se puso a ojear las confesiones de los demás. Lo primero que buscó fue sin demora el espacio de la Lucía. Estaba su nombre mas no había nada más. Tampoco la Maruja había escrito nada. De los hombres, sólo el Juan y el Chino habían contestado a una que otra pregunta. En cambio, la Carmen, la Rosa y la Mariela, las tres marías, quién se metía con ellas, tenían casi todas las preguntas saldadas; aunque había muchas hojas en blanco para inventar otras. Para el final del verano, aseguraba la Carmen, todos habrían apuntado su historia. Todo estaría registrado en aquel cuaderno forrado con papel azul con un corazón rojo en cada tapa y en el centro un tú y en el otro un yo y que llevaba el inofensivo título de cuaderno de preguntas y respuestas perteneciente a Carmen Berríos.

Quién sabía cómo o de dónde sacaban las preguntas o la idea misma de hacer algo tan, ajá, femenino. Eso era, a ellos, hombres, nunca se les hubiera ocurrido diseñar un cuaderno con esas características. No había caso, los hombres y las mujeres eran seres muy distintos. Como si al enfatizar las diferencias justificaran el miedo, la vergüenza ante los ojos de ellas, ahí, mirando, mientras el Oso pedía una tregua. El cuestionario era demasiado largo. Las preguntas eran difíciles, mejor dicho, mejor hacerlo con calma, de a pocos. Pero ellas no le creían. Y se notaba en ellas un aire de triunfo, diciendo con los ojos que al margen de lo que él quisiera o no, y así mintiera, de todas maneras dejaría un fiel retrato de quién era él.

- ¿Y qué contestaste en ésa donde te pedían algo sobre tu mujer ideal? No, no era así sino algo que ver con artistas. 
Tenía buena memoria. Además cómo olvidarse de cosas así. Porque las tres marías eran unas fanáticas enamoradas del insoportable de Raphael. Y habían escrito Raphael o Robert Redford, Raphael o este otro, pero siempre él como primera opción. El Juan había puesto que su sueño era casarse con la Sofía Loren. Quien sí se pasó fue el Chino, como de costumbre, aguando la fiesta. El había escrito con letra imprenta que No. No deseaba casarse con ninguna artista ni soñaba tener relaciones con ninguna de esas tontas. No le interesaban. Claro, el Chino inevitablemente era quien peor les caía a ellas, sobre todo a la Carmen. Ella no dejaba de tratarlo de espeso, de idiota, etcéteras, para no mencionar las cosas que diría de él entre mujeres solas. Pero tenía razón. Porque el Chino tenía un extraño talento para molestarlas, ya sea con su presencia o su voz tan bien entrenada, educada. Iba a ser locutor de radio y televisión. Aunque no hablaba tanto de la televisión por temor a que se burlaran de él. Para la radio era ideal, sin dudas. En cambio, si a la voz se le agregaba su cara, ya no. Y la Carmen no perdía oportunidad para recordárselo, especialmente cuando se ponía a hablar de su consagrado futuro como comentarista de fútbol y política. Nadie apagaría la radio o la televisión cuando él realizara sus entrevistas candentes. Lo que sí, cuando la Carmen estaba presente, él siempre se cuidaba de no excederse. Sabía que ella andaba al acecho. Con decir que una tarde, delante de todos, adultos también, alla lo gritó sin miramientos por tratar a las mujeres como si todas fueran unas putas. No obstante, o tal vez por eso mismo, el Chino cada día se convencía del amor que la Carmen le profesaba. Ella, según el raciocinio de él, estaba enamorada, locamente, de él. Pero como él no le daba bola, ella se vengaba de esa manera. Nada peor que una mujer despechada, repetía, como si hubiera sido muy fácil imaginar a una chica enamorada de él con la cara que se manejaba.

-Mira, mira...

El Fernando le dio un codazo. Todas ellas salían de la casa de la Mariela. A contraluz, las siluetas se delineaban nítidamente. La Yolanda caminaba detrás de todas; su silueta se diferenciaba de las del resto no tanto por su caminar como por sus formas; era casi una mujer, no, más que una mujer. Las demás eran unas niñas aun considerando sólo el aspecto físico, la silueta. Echados boca abajo los dos contemplaban la procesión en silencio. El Fernando estiró el brazo y le sacó la cajetilla del bolsillo de la camisa al Oso. Con el cigarrillo apagado entre los labios se sintió inclinado a expresar su parecer sobre cada una de las sombras que no muy lejos de las casas, justo entre ellos y los demás, reunidos más allá, se sentaban ahora sobre la arena acaso esperando que los chicos fueran capaces de reunir el valor necesario para ir hacia ellas y ganar la noche juntos. Hubiera sido tan distinto, una vez más el Oso arremetiendo contra don Armando, una bestia, como corresponde, si la Lucía pudiera salir por la noche, sí, hubiera sido otra cosa.

$-\imath$ Tú crees que ellos se animen? 
A saber. Seguramente el Edy sería el más empeñoso y utilizaría cualquier pretexto para estar cerca a la Rosa. Aunque todo dependía de que el Chino y el Juan se pusieran de acuerdo. El Mañuco no contaba.

Y ahí estaban, las tres marías, contándose sus secretitos. La Maruja también, de aspirante; pero más arriesgada que las demás, menos ruborosa, a veces despiadada con sus verdades, desenvuelta e irreverente con ellos, todavía no le había bajado la regla, sin nada que perder, aniñando la conversación como diría el Chino. Y la Yolanda de cuidadora. A la niña Mariela no la dejaban salir por la noche sin ella. La chola feliz de jugar como una igual con las chicas. Pero el Fernando perdía toda objetividad con ella. Hasta le dolía cuando hablaban de la Yolanda como una chola más, la simple sirvienta de los Mendiola. Claro, la mayoría de las veces no decía nada, no la defendía. Se cuidaba de no expresar aquello que le picaba adentro y lo obligaba a apartarse de los otros cuando ya no podía disimular más. No obstante, a pesar de cuidar las apariencias ya lo habían comenzado a molestar con la Yolandita esto o esto otro o a tacharlo de cholero. No mucho pero algo, lo suficiente para no saber qué hacer, salvo hacer el que no escucha, camuflar mejor las acciones, las palabras, desde luego.

- ¿Nos vamos?

Caminando. Sí, el Edy seguiría insistiendo. El Chino sería el más difícil de convencer. Todas ellas estarían probablemente jugando y esperándolos, la Yolanda también, a pesar de sentir cierta repulsión. $O$ tal vez fuera vergüenza, temor, sólamente, de esas miradas, ojos que las hacen ruborizarse sin saber de qué, riéndose bajito como unas tontas. Aunque siempre ellos más, mucho más tontos. Porque si tenían algo que decir o tomar la mano, ensayar una caricia, no lo hacían, por lo menos nunca en el momento en que era dado. Contar chistes, eso sí. En eso nadie los ganaba. Pero por lo general se pasaban de groseros. En lugar de crear una mayor intimidad y acercamiento, las alejaban. Les daban asco con sus risas repletas de deseos taconeados muy al fondo, tan adentro que no daban ganas de estar con ellos. Y la cara de idiotas que ponían, de culpables, niños babeando. El Chino, aunque espeso e insoportable, por lo menos hablaba de manera más directa, con menos escondites en la lengua. En cambio el Edy y el Juan no salían de sus secretitos, insinuaciones encubiertas. Por supuesto, el Juan era el más guapo, sin lugar a dudas; ellas estaban convencidas de que sería un mujeriego incorregible. Las cosas que se les ocurría imaginar sobre lo que ellas podrían estar pensando o diciendo al Fernando y al Oso. Y la Carmen enfatizaría que el Oso era demasiado huesudo, la nariz muy larga, espantosa la manera como se dejaba crecer los cuatros pelos en la cara; tal vez él creía que a eso le podían llamar barba. Sin embargo había que reconocer, el Fernando se lo había escuchado a la misma Mariela, que sus pestañas, uy, lo máximo, eran soñadoras; y cuando fumaba se ponía irresistible. El Edy sería el colmo de la timidez; el Fernando, buena gente, 
pero un poco gordito para el gusto de ellas, pero un poco nomás. La Yolanda no diría mucho, tan sólo se reiría, la primera en reírse tal vez. Mas nunca se pasaría de la línea. La Yolanda sabía cuál era su sitio a la perfección; siempre estaba como debía de estar. Además tenía esa manera de ponerse seria, de mirar como llamando la atención. Hasta las tres marías la obedecían sin reclamos. Estaba buena la chola.

Se detuvieron a una distancia prudente de la casa. La ausencia de luna casi les permitía la ilusión de ser invisibles. La marea, en plena baja, como para ir a sacar pejesapos. Y podiá ser la emoción, los nervios, en todo caso era fácil sentir esa noche de manera especial, el momento ideal para iniciar algo importante, ¿no decían así a cada rato los horóscopos? Otro cigarrito para repensar el plan. La Lucía era géminis. Si por lo menos el suegro no fuera tan grande y tan feo. Se echaron sobre la arena. Ocasionalmente, a través de las cortinas, alguna sombra proyectaba su paso desde la casa. Las dos ventanas eran pequeñas, demasiado chicas para el tamaño de la casa. No, no era una casa; sino una fortaleza impenetrable. El mismo don Armando la había diseñado, seguramente pensando en la hija, en los enamorados que tendría. Ya que habían llegado hasta ahí, lo mejor que podían hacer era tranquilizarse, preparar bien la visita.

-Oye, fumar ésto es como fumarse un chíclet, ¿ah?

Habló el Oso dando la impresión de haber tenido mucho tiempo aquella frase en gestación, para que el Fernando asintiera con admiración o algo por el estilo. Porque había ciertas cosas básicas que era necesario conocer. Su primo, no mucho mayor que él, pero lo suficiente, se lo había dicho, se lo repetía siempre. El Oso lo admiraba mucho; era un experto en estos asuntos y estaba más que dispuesto a contarle quién era o cómo le había salido su última conquista. No había nadie como su primo. En una época, y a él le constaba, no como otros que son pura boca, su primo llegó a tener tres enamoradas al mismo tiempo. Y fue en aquella época cuando lo aconsejó en materia de cigarrillos y de chíclets, los dos elementos más importantes, según su primo, para que el primer beso surta efecto. Había que ser muy cuidadoso, tan cuidadoso como cuando lo haces con una hembrita virgen. Así era, tabaco, chíclet y perfume. Sobre esos tres elementos descansaba gran parte del éxito; su combinación era crucial, sobre todo al principio, cuando uno no está seguro del sí o del no. En su vastísima experiencia había descubierto, su primo por supuesto, que a ciertas chicas les molestaba el sabor a tabaco, ése que queda ahí en la boca. Entonces, había dos soluciones muy prácticas: masticar un chíclet después o durante el cigarrillo, o fumar mentolados. La segunda alternativa era, según el primo, la más adecuada para comenzar, la más barata también. Su primo realmente pensaba en todo. Una vez que ya uno ha perfeccionado, aunque no es uno sino los dos, la pareja, no se acordaba el Oso si su primo había dicho pareja o no, en fin, sólo una vez familiarizados con algunas de la infinitas variantes y combinaciones del humo boca a boca 
era menos difícil agregar el chíclet. Lo que sí, una advertencia. Su primo no era sólo irresistible con las mujeres sino un buen estudiante de medicina; iba a ser raya con las enfermeras. No era aconsejable fumạr mucho mentolado; secaban las hormonas masculinas y uno podía terminar convertido sin saberlo en maricón.

El secreto, lástima que el Fernando no conociera a su primo, era no apresurar las acciones pero ser firme en cada paso, sin vuelta atrás. Y que siempre recordara que lo mejor no es el primer beso. Había mucho, todo un universo detrás de un beso. Tenía que buscarse chicas con imaginación y curiosidad, de lo contrario todo el trabajo recaería sobre él. Ya vería. Lo más difícil era comenzar. Y nada más rico para preparar la boca, la garganta, la lengua, los pulmones, perfumar el cuerpo interiormente, purificarlo para el encuentro con ella. Sí, los cigarrillos, los chíclets, parte fundamental. A él le correspondía iniciarla a ella. Tal vez las primeras veces la Lucía se pondría colorada; pero luego superaría el rubor y le agarraría el gusto. Se pasarían el humo con lengua o sin lengua, por el costado de la boca o a boca llena, por la nariz también, cuántas pasadas de humo serían capaces de hacer sin que se escapara por el aire, con el chíclet, uyuyuy, y la saliva, claro, un mundo por delante. Además el Oso tenía el vago presentimiento de que con la Lucía, una vez superada la vergüenza inicial, podría llegar muy lejos. Se enseñarían mutuamente, ay Lucía.

- ¿Tu escribiste en el cuaderno que te gustaba la Lucía?

Lo primero fue guardar el secreto. Y eso fue lo que pensó hacer al leer la pregunta. Pero por qué negarlo. Le pareció ridículo mentir, hacerse el loco. Uno o dos años atrás seguramente se hubiera tragado el secreto y muerto con él. Sin embargo ahora, ajá, ahí estaba la diferencia. Se iba haciendo hombre. Más aún, al escribir Lucía sobre la página, y la Carmen con la Rosa se hacían las que no miraban pero lo hacían de reojo, cómo eran ¿no?, tuvo la certidumbre de que de esa manera allanaría el camino hasta ella. Porque una vez que todos saben y ella también, entonces no queda mucho por hacer, sólo seguir la ola y terminar revolcado en los brazos de ella con su bikini verde.

- Cuando tengas mi edad ya no te van a molestar esas cosas. Por algo uno se hace viejo, huevón.

Debía ser como lo decía el Oso. Pero le resultaba imposible, lejanamente imposible la llegada de aquel día libre de lo que digan los demás.

- ¿Y no tienes miedo de que lo sepan tus viejos?

Porque si para el Fernando era improbable la existencia de un día en el cual la opinión de los demás no lo atenazara, si se ponía a pensar en sus padres la insignificante dosis de esperanza se le evaporaba. Ellos nunca entenderían. No podía ser, simplemente. El día que él se enamorara, así como el Oso, lo de la Yolanda no podía ser igual, tendría que estar dispuesto a irse de casa. Eso de que sus padres también habían sido jóvenes y alguna vez se habían enamorado, como le decía el Oso, no lo conven- 
cía. Podía ser cierto. Pero si alguna vez habían sido jóvenes, y todo lo demás, ya se habían olvidado. Lo mismo que nada. Y apreciaba el optimismo del Oso. Esperaba, sin embargo, que llegado el momento no le faltaran las fuerzas necesarias para agarrar sus maletas y decir adiós a sus viejos. No, no los odiaba. Es que no podía estar en casa y enamorado al mismo tiempo, simplemente.

- Bueno, nos aventamos o qué.

Definitivamente se hacía tarde. O acaso era sólo la noche sin luna, estar ahí tirados, mirando como tontos las dos ventanas de la casa, en medio de nada, oscuridad nada más, ni bulla o voces, sin dejar de mirar hacia la casa como si por intensidad de mirada, telepatía, don Armando fuera a caer dormido, hipnotizado, y la Lucía saliera a invitarlos, no, no, no, que saliera sola más bien a sentarse con ellos bajo las estrellas.

$-i Y$ el perfume?

En algún punto de la noche tenía que haberlo mencionado ¿no? Mas el Oso acudía a las enseñanzas de su primo. Cómo podía un mocoso rebatir la sabiduría de su primo Carlos que, no como los demás, tenía hechos y no palabras que lo acreditaban, no una sino muchas chicas, aparte de las que se morían por él sin que él les diera bola. No podía ser malo usar perfume, aunque sí, después de todo. Lentamente el Oso comenzaba a olerse a sí mismo y a acordarse de la nariz de don Armando. Otro cigarrito y a hacer más tiempo. El perfume tenía que evaporarse. Qué buena idea había sido echarse a meditar bien el plan. Cambiar de tema. Preguntar por la Rosa y el Edy, el Juan y la Carmen, acaso el Fernando pensaba que fueran posible semejantes combinaciones. Y del Chino qué. Pues nada. Porque él estaba dispuesto a prescindir de ellas; a pesar de que le gustaban todas y ninguna en particular. Nadie le creía al Chino, claro. Todos tenían la inconfundible sospecha de que las justificaciones dadas eran a lo sumo máscaras, disfraces bien formulados con su lengua de locutor. Era por feo y ahí se acababa la discusión. Bueno, en realidad no se quedaba ahí porque el Chino exigía ser escuchado, que los demás sean objetivos; la objetividad era, según él mismo, el alma del locutor; que vieran a su alrededor, en el hombre ser feo era un punto a favor si es que se sabe sacar provecho del poder de la voz. Y como ejemplo más mentado siempre lo tenía que poner a don Armando. Que miraran y lo contradijeran. Doña Giovanna todavía, a pesar de los años, se conservaba muy bien; debía de haber sido más rica que la Lucía aún. Las cosas con las que salía el Chino. Pero con él sí se podía tener la seguridad, por lo menos en este verano, de que no iba a hacer nada. El Juan y el Edy, quizás; sólo que a los dos les gustaba la chica equivocada. A la Carmen el Juan nunca la conquistaría. Menos el Edy con la Rosa. Si intercambiaban pareja, a lo mejor. Sin embargo no se podía esperar semejante acuerdo. Los dos prácticamente peleaban todo el día. Y cuando estaban con ellas, en vez de ayudarse, se hacían la vida imposible, burlándose el uno del otro con insultos y todo. Una vaina. Enamorar a una chica tenía que ser la cosa más difícil en el mundo. 
- Oye, cuñado, y de verdad que andas detrás de la Yolanda.

No, no la perseguía. Eso no era así. Quién le había dicho. El Fernando aspiró el humo imitando casi inconscientemente al Oso. Era un juego nada más. Y era, había sido una tontera pensar que iba a ser un secreto. En todo caso aquello nunca quedaría consignado en el cuaderno de la Carmen. Un juego. A la Yolanda le gustaba jugar a esas cosas con él. Pero no habían hablado mucho. Era más que nada así como mirarse. Cuando él hablaba algo, y ella estaba presente, sólo con mirarlo de esa manera lo hacía verse, como un idiota. Y él se vengaba también. Por ejemplo, no le quitaba la vista de las piernas hasta que se diera cuenta que la estaba mirando para seguir en el mismo plan a ver qué pasaba. La mayoría de las veces ella terminaba riéndose de él. Cómo volaba el chisme. Y él pensando que nada era obvio. Porque parecía que nadie se daba cuenta, todo seguía de lo más normal, cuando ellos jugaban muy secretamente, por encima o debajo de los demás.

Sólo una vez él la había tocado, una casualidad. Unas noches atrás, la Yolanda estaba sentada a su lado, él se paró para ir a traer la guitarra de la casa del doctor Zevallos, a ver si se la prestaba esta noche también, y sin darse cuenta le rozó los senos con el brazo izquierdo. No había sido intencional. Pero al sentir el busto de la Yolanda que respiraba contra su brazo se demoró en pararse, manteniendo el brazo ahí. Claro, desde esa noche la Yolanda no quiso jugar más. Por temor a que los demás se dieran cuenta ni se había movido. Recién ahora estaba volviendo a recuperar la confianza en él. Quizás esperaba unas disculpas. Aunque en el fondo eso fue lo que hizo hace unos días, apenas tres mañanas atrás.

-O sea que hasta ahora nones, cero.

El Fernando asintió, levantando los hombros. Sin embargo aún le faltaba hablar de lo más importante, de lo que casi era algo más que cero, mucho más de lo que nunca había llegado a alcanzar con nadie.

Fue el domingo pasado, tempranito. El había bajado a la orilla a hacer tiempo. Los domingos siempre en su casa se desayunaba tarde. Ni soñaba encontrarla. Y estaba ahí, con su vestido azulito, el de siempre, bien entallado pero no tanto. Ella limpiaba unos pescados sentada sobre las rocas, al lado de la poza de los erizos. Aparte de dos pescadores, mucho más allá, no había nadie en la playa. Era demasiado temprano.

No, no se acercó directamente. Por un tiempo estuvo correteando cangrejos, acercándose a ella. Después de haber capturado uno, de los más grandes y colorados, decidió caminar hacia ella, sentarse cerca, como para conversar, casi frente a frente. Un pocito de agua, en el cual ella lavaba los pescados, los separaba. Ella no lo saludó ni nada; siguió en lo suyo. Ocasionalmente, al agacharse a limpiar el cuchillo en el agua, el vestido se le subía un poco. Sabía que él la miraba. No obstante, actuaba como si él no estuviera ahí, él, con el cangrejo colorado en la mano derecha agitando sus tocolas. Y fue quién sabe por qué razón, tal vez para que lo mirara de una vez, para que no siguiera haciéndose la desentendida que 
soltó el cangrejo en el pocito. La Yolanda dejó de desescamar pero no lo miró. El cangrejo se hundió como un submarino rojo; tocó fondo; se orientó bajo el agua y salió caminando como si nada; ni siquiera pisó una sola de las agallas con sus seis patas. Sólo cuando el submarino hubo salido del agua la Yolanda lo miró a los ojos. Se rió un poco. Y siguió en su faena sin levantar la vista por mucho tiempo. Finalmente, ya le faltaba sólo un pescado, eran dos corvinillas y dos lenguados, el Fernando se atrevió a preguntarle si le gustaba el pescado frito pero pensando, más bien, que debería disculparse por lo de la otra noche.

Y ella siguió igual, como si no hubiera escuchado nada. Durante aquel silencio fue cuando más descaradamente le miró las piernas. Con el sol de la mañana su piel era de color caoba. No se detuvo en el cuello. Por el escote sospechó lentamente lo que había debajo. Sí, cuando él tenía los ojos sobre el escote ella dejó de limpiar el lenguado y lo apuntó severa con el cuchillo lleno de escamas. Y dijo sí, esta vez los ojos de ella lo volvían a él ridículamente vulnerable. Repitió el sí una vez más, menos seria, pero ya sus ojos se iban. El cuchillo regresaba a cumplir su función. Cortándole las tripas al lenguado agregó que sobre todo en el desayuno. No había nada más rico que pescado frito en el desayuno también para él. El sol de la mañana estrellaba las sombras muy largas sobre las rocas húmedas. No se dijeron nada más.

- ¿Nada más?

Bueno, sí, mas de despedida, cuando los cuatro pescados estuvieron bien acomodados en el balde y ella se acomodó el vestido con modestia, lista para irse sin mirarlo siquiera. El Fernando hubiera querido acompañarla y sólo pudo llamarla: Yolanda. Se le salió así nomás. Se dio cuenta que la voz le había salido más gruesa que de costumbre y no pudo evitar sonreírle. Ella se detuvo. Y él entonces fue a decirle que le prometía esperarla todas las noches, cuando todos se hayan acostado, detrás de las casas, de la casa de los Macedo. Que la estaría esperando. Ella vería seguramente el fuego del cigarrillo a lo lejos.

- Así que cholerito el niño Fernando zah?

Eso mismo se lo hubieran dicho los demás. El Oso había dicho aquello para que se riera un poco. Y el Fernando esta vez se puso serio. Por algo le preocupaba tanto que los demás lo supieran. Para qué entonces se lo había contado a él. Desilusionado del Oso ya no lo miraba, tampoco la casa de la Lucía. El Fernando miraba el mar impenetrablemente serio. Para qué le fue a contar esas cosas al Oso. Se estaba riendo de él ahora. No podía confiar en nadie en este mundo. El Oso sólo atinó a ofrecerle un cigarrillo. Lo de cholerito le seguía dando vueltas y ya no sabía ponerse más serio o más silencioso. El Oso masculló algo. Le volvió a ofrecer un cigarrillo y esta vez el Fernando aceptó.

No podía tomarse esas cosas tan en serio. El Oso hablaba con dificultad. Eran palabras que se decían para expresar otras emociones. Que no fuera tan mal pensado. El Oso comprendía. Y también a él le había pasado 
algo parecido hace un año. El Fernando tenía que tenerle un poco más de confianza. No, no se lo iba a decir a nadie.

-No me digas que ahora tú resultas un cholero, conchetumadre.

El Oso encendió su propio cigarrillo para acompañar las palabras, para darles algo de peso. Porque de vez en cuando sucedía que lo ocurrido se le desvanecía; llegaba a dudar con mucha facilidad de eso que pasó entre él y la Mercedes. No, el Fernando no la conocía. Bien podía no haber sucedido. Al fin y al cabo, siempre pensó que después de hacerlo el mundo sería distinto, o por lo menos él. Algo así como tatuarse el brazo, algo, una marca imborrable, inequívoca que lo diferenciaba a uno de los demás. Sin embargo ahora no estaba seguro. El Fernando no la llegó a conocer; duró muy poco trabajando en la casa. Quizás su mamá llegó a sospechar algo y la echó. No sabía.

- ¿La grandota, ésa del Cuzco?

Cómo podía haberla conocido el Fernando si hace un año no eran amigos. Que no, y no insistiera. Curiosamente, con el paso del tiempo, la Mercedes había vuelto a ser Mercedes. Porque él le puso Segismunda. Y mientras estuvo trabajando nadie la llamó por su verdadero nombre. Es que tenía cara de Segismunda. Mientras el Oso hablaba, aunque callaba quizás más de lo que decía, fumaba con la mano derecha y con la izquierda hacía cataratas de arena. Y una tarde, así como lo decía, sí, una tarde de regreso del colegio ya no la encontró en casa. Al día siguiente supo por boca de su abuela que su mamá la había largado por floja.

$-i Y$ ?

Como si eso fuera todo. Después de tres palabras se callaba y amenazaba con decir eso es todo. Pero le sucedía al revés. Le quedaba tanto por contar. Más de un año ya que no iba a misa. No había podido confesar lo ocurrido. Y sentía cierta vergüenza acaso por tener las cosas tan guardadas. O por el recuerdo, la torpeza del principiante cuando pretende ocultar su ignorancia tras una fachada, cara de niño sabelotodo. Dónde estaría la Segismunda nuevamente Segismunda después de todo ese tiempo. El Oso tuvo que sonreír mientras echaba el humo. Así lo ordenaba el pasado. Segismunda por lo astronauta, en las nubes, como una ninfa del campo. Porque nunca dejó de oler a tierra y a papas por más que se bañaba. Cuando la abuela la llamaba parecía gritar a otro mundo. Aunque lo más llamativo de su persona era la risa. Su mamá se volvía loca cuando, con visitas en la casa, estallaba en algún rincón de la casa aquella risa de loca encantada de la vida. Claro, él la buscaba por las partes de la casa donde los demás no podían verlos y ella acudía como una tonta. Pero más tonto él, sobre todo en esas semanas que no sabía qué hacer para pasar de las palabras a la acción, idiota, estúpido, reprobando casi todos los cursos menos Dibujo y Educación Física. Su papá lo iba a matar cuando recibiera la libreta.

Nada especial, un poco gordita pero bien formada. Nunca había experimentado de esa manera, sin embargo, la urgencia de tocar, palpar y 
haste morder a una mujer. Por las noches, después de conversar con ella detrás del jardín, donde ella lavaba la ropa por las tardes, sentía la obligación de masturbarse pensando en ella, imaginando lo que no sabía hacer. Fue en esa época también cuando leyó cualquier cantidad de libros sobre educación sexual; pero ninguno de ellos decía nada sobre lo más importante: cómo llegar al punto después del cual vale la pena saber lo que esos mismos libros contenían. $\mathrm{Y}$ aunque sabía que memorizar las diferentes partes del órgano sexual femenino no lo iba a ayudar, de todas maneras lo hizo. No sabía qué hacer.

- ¿Y los amigos? ¿no podías acaso preguntar?

Tenía, y algunos mucho mayores que él, de los que ya lo habían hecho y todo. Pero no hubiera sabido qué preguntar. Además, para él aquello era un secreto. O tal vez fuera sólo timidez, miedo, tantas cosas. No hubiera soportado que le preguntaran sobre la Segismunda. Por lo menos tenía el cine. Ahí aprendía algo o simplemente se olvidaba de ella por un rato. Aunque el desencanto no se hacía esperar. Porque todo parecía tan fácil en las películas, aparte de que casi nunca se trataba de adolescentes sino de gente grande con carro, dinero para pagar un hotel, experiencia o por el contrario, mujeres seductoras. Además, siempre cortan las películas en la mejor parte. Un tiempo inenarrablemente largo anduvo así.

Hasta que una tarde, después del colegio, salió todo sin planear, cosa del momento. Nadie lo hubiera imaginado.

- Cuenta, cuenta, huevón.

Bueno, aquella tarde regresó del colegio con la pierna adolorida. Jugando fútbol, el marciano Lizárraga le había dado un patadón en el muslo. Sólo la abuela estaba en casa, bordando en el comedor. La radio tocaba un programa de cumbias. A la Segismunda le encantaban las cumbias. Y, como de costumbre, sin cambiarse el uniforme, fue a ver si ella estaba lavando, para conversar, cosas de siempre, de las clases aburridas, los profesores despóticos, unos sádicos, chistes, bromas de los recreos.

-Ya, ya, huevón, no seas detallista.

La cosa es que ella estaba ahí. Había terminado de lavar la ropa y se lavaba el cabello cuando la encontró. El Oso comenzó a hablarle y no podía sacar los ojos de su cuello, su cintura. La blusa se le había mojado un poco y se le pegaba al cuerpo, una tortura, al mismo tiempo que se quejaba profusamente, para llamar la atención, de la pierna adolorida. Entonces fue que se le ocurrió lo del masaje, así como así. Cómo no había pensado en eso antes. Había sido realmente un tonto. Sí, la bestia Lizárraga, el marciano loco, como le decían, le había dado una patada de pura rabia. Porque no le pudo meter el gol. Y estaba solito. El marciano solito frente a él. Pero como era una bestia, había picado demasiado la pelota y él se había lanzado, de cabeza, volando como una pantera, como sólo él sabía volar, nadie le metía un gol así nomás. Justo al caer al suelo y abrazar la pelota sintió el patadón de la bestia marciana. Que le diera una frotadita. Ella sabía que sus mejores tapadas se las dedicaba a ella. Que 
no se preocupara si no sabía masajear. El le enseñaría. Y la hizo sentarse en el pasto, bajo la higuera, con las faldas arremengadas para enseñarle el difícil arte de las frotaciones musculares. Por ella, él sería capaz de morir aplastado por el marciano o quien fuera.

- Puta, te pasaste, cuñadito.

El Oso encendió otro cigarrillo y volvió a mirar hacia la casa de la Lucía como disculpándose por haber estado con la cabeza puesta en otros asuntos. Se hacía tarde, muy noche ya para ir a visitarla. No obstante, ninguno de los dos dijo nada sobre la hora. Luego el Oso retomó la palabra.

-Y esa no fue la única vez.

Muchas tardes jugaron a lo mismo. Muslo, cadera, pecho, senos, estómago, espalda, cuello, siempre una parte que descubrir, entrepierna. Y en ocasiones, la boca tuvo que aunarse a las manos para cumplir las exigencias del momento. A veces era bajo la higuera; otras, en el cuarto de ella. Pero nunca llegaron a hacerlo, hasta esa noche. Y cuando lo hicieron, en esa última vez, no hubo juego, ni parte del cuerpo como pretexto para acariciarse. Masculinamente duro, petrificado, no hizo nada, salvo tirarse sobre la Segismunda sin murumurar palabra. Al parecer, ella, desde el instante en que notó su presencia en el cuarto a esas horas de la noche, sabía lo que vendría y lo guió como a un ciego. A través del condón sintió algo, quién sabe. Segundos después ya se había parado nervioso, nada de palabras, y cerraba la puerta apresurado. El Oso fumaba sin mirar a la casa de la Lucía.

\section{- ¿Vamos regresando?}

Caminaron como con frío. Seguramente el suegro ya la había mandado a acostarse a la Lucía. La marea parecía más baja aún. Al pasar por donde todas las demás habían estado reunidas ya no había nadie. En el silencio y la oscuridad sin luna, sólo las voces del Chino y el Edy se proyectaban nítidas del lugar de siempre. El Fernando se detuvo y le pidió dos cigarrillos. No, no iba con el Oso adonde ellos. Ya era tarde. A lo mejor esta noche la Yolanda se animaba. Tres noches seguidas que la esperaba. Unos cigarritos para la espera, mejor tres. Mañana él lo acompañaría también si quería, pasado, no importaba. Pero sería más fácil si llegaba a algo más concreto con la Lucía. Que aprovechara el día también. Para ganar confianza y no quedarse tirados ahí como unos tontos.

W. Enrique Lizárraga California, abril, 1985 